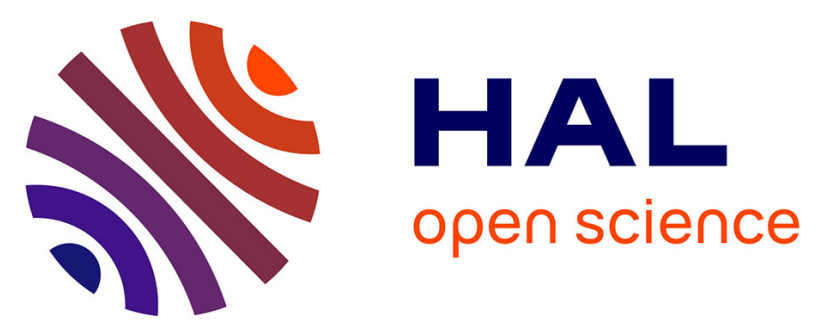

\title{
Liposomes for PET and MR imaging and for dual targeting (magnetic field/glucose moiety): synthesis, properties and in vivo studies
}

Jeremy Malinge, Bastien Géraudie, Paul Savel, Valerie Nataf, Aurelie Prignon, Claire Provost, Yongmin Zhang, Phalla Ou, Khaldoun Kerrou, Jean-Noel Talbot, et al.

\section{To cite this version:}

Jeremy Malinge, Bastien Géraudie, Paul Savel, Valerie Nataf, Aurelie Prignon, et al.. Liposomes for PET and MR imaging and for dual targeting (magnetic field/glucose moiety): synthesis, properties and in vivo studies. Molecular Pharmaceutics, 2016, 14 (2), pp.406-414. 10.1021/acs.molpharmaceut.6b00794 . hal-01427809

\section{HAL Id: hal-01427809 \\ https://hal.sorbonne-universite.fr/hal-01427809}

Submitted on 6 Jan 2017

HAL is a multi-disciplinary open access archive for the deposit and dissemination of scientific research documents, whether they are published or not. The documents may come from teaching and research institutions in France or abroad, or from public or private research centers.
L'archive ouverte pluridisciplinaire HAL, est destinée au dépôt et à la diffusion de documents scientifiques de niveau recherche, publiés ou non, émanant des établissements d'enseignement et de recherche français ou étrangers, des laboratoires publics ou privés. 


\title{
Article
}

\section{Liposomes for PET and MR imaging and for dual targeting (magnetic} field/glucose moiety): synthesis, properties and in vivo studies

\author{
Jeremy Malinge, Bastien Géraudie, Paul SAVEL, Valerie Nataf, Aurelie
}

Prignon, Claire Provost, Yongmin Zhang, Phalla Ou, Khaldoun Kerrou, Jean-

Noel Talbot, Jean-Michel Siaugue, Matthieu Sollogoub, and Christine Menager

Mol. Pharmaceutics, Just Accepted Manuscript • DOI: 10.1021/acs.molpharmaceut.6b00794 • Publication Date (Web): 28 Dec 2016

Downloaded from http://pubs.acs.org on January 3, 2017

\section{Just Accepted}

"Just Accepted" manuscripts have been peer-reviewed and accepted for publication. They are posted online prior to technical editing, formatting for publication and author proofing. The American Chemical Society provides "Just Accepted" as a free service to the research community to expedite the dissemination of scientific material as soon as possible after acceptance. "Just Accepted" manuscripts appear in full in PDF format accompanied by an HTML abstract. "Just Accepted" manuscripts have been fully peer reviewed, but should not be considered the official version of record. They are accessible to all readers and citable by the Digital Object Identifier (DOI®). "Just Accepted" is an optional service offered to authors. Therefore, the "Just Accepted" Web site may not include all articles that will be published in the journal. After a manuscript is technically edited and formatted, it will be removed from the "Just Accepted" Web site and published as an ASAP article. Note that technical editing may introduce minor changes to the manuscript text and/or graphics which could affect content, and all legal disclaimers and ethical guidelines that apply to the journal pertain. ACS cannot be held responsible for errors or consequences arising from the use of information contained in these "Just Accepted" manuscripts. 


\title{
Liposomes for PET and MR imaging and for dual targeting (magnetic field/glucose
} moiety): synthesis, properties, and in vivo studies

Jérémy Malinge ${ }^{1,2}$, Bastien Géraudie ${ }^{3,4}$, Paul Savel ${ }^{1,2}$, Valérie Nataf ${ }^{4}$, Aurélie Prignon ${ }^{3}$, Claire Provost ${ }^{3}$, Yongmin Zhang ${ }^{2}$, Phalla Ou ${ }^{5}$, Khaldoun Kerrou ${ }^{4}$, Jean-Noël Talbot ${ }^{3,4}$, JeanMichel Siaugue ${ }^{1}$, Matthieu Sollogoub*2, Christine Ménager* ${ }^{1}$

1 Sorbonne Universités, UPMC Univ Paris 06, CNRS, UMR 8234, PHENIX, F-75005, Paris, France 2 Sorbonne Universités, UPMC Univ Paris 06, CNRS, UMR 8232, IPCM, F-75005, Paris, France 3 Laboratoire d'Imagerie Moléculaire Positonique (LIMP), UMS028 Phénotypage du petit animal, UPMC Univ Paris 06, Paris, France 4 Médecine nucléaire et radiopharmacie, Hôpital Tenon, AP-HP, Paris, France 5 Université Paris Diderot, Plateforme de recherche préclinique FRIM, 46 rue Henri Huchard 75018 Paris, France

* corresponding authors : christine.menager@upmc.fr, matthieu.sollogoub@upmc.fr

\begin{abstract}
We describe the potentiality of a new liposomal formulation enabling PET and MR imaging. The bimodality is achieved by coupling a ${ }^{68} \mathrm{Ga}$-based radiotracer on the bilayer of magnetic liposomes. In order to enhance the targeting properties obtained under a permanent magnetic field, a sugar moiety was added in the lipid formulation. Two new phospholipids were synthesized, one with a specific chelator of ${ }^{68} \mathrm{Ga}$ (DSPE-PEG-NODAGA) and one with a glucose moiety (DSPE-PEG-Glucose). The liposomes were produced according to a fast and safe process, with a high radiolabeling yield. MR and PET imaging were performed on mice bearing human glioblastoma tumors (U87MG) after $i v$ injection. The accumulation of the liposomes in solid tumor is evidenced by MR imaging and the amount is evaluated in vivo and ex vivo according to PET imaging. An efficient magnetic targeting is achieved with these new magnetic liposomes.
\end{abstract}

Keywords: PET, MRI, gallium, magnetic nanoparticles, liposomes, magnetic targeting, Warburg effect

The combination of positron emission tomography (PET) and magnetic resonance imaging (MRI) into a single hybrid imaging modality using a common radiopharmaceutical and contrast agent has attracted the interest of many research groups, worldwide, for addressing 
major medical needs ${ }^{[1-5]}$. Such an imaging tool combines the advantages of both imaging techniques, thus minimizing their respective limitations. For instance, MRI provides a high spatial resolution and great insight into the functions of surrounding organs. However, this technique only provides relative quantitative evaluation. In contrast, PET radiotracers allow absolute quantification of the uptake of the positron emitting radiopharmaceuticals with a detection limit in the pico-molar range. Such a bimodal imaging probe could offer complementary information and could be a very interesting tool for the development of theranostic platform ${ }^{[6]}$.

The most widely used contrast agents for T2 pondered sequences in MRI are based on iron oxides, ${ }^{[7]}$ appearing as hyposignal areas on images. In this context, the encapsulation of magnetic nanoparticles (MNPs), for example, maghemite $\gamma-\mathrm{Fe}_{2} \mathrm{O}_{3}$ nanoparticles (NPs), in the aqueous core of liposomes provides ultra magnetic liposomes (UMLs) as an efficient material for MRI imaging. From the encapsulation of superparamagnetic NPs inside liposomes arises an increase of their intrinsic relaxivities, thus allowing a more accurate diagnosis in vivo ${ }^{[8]}$. Moreover, due to their high magnetic payload, UMLs are able to accumulate in solid tumors as well as in healthy tissue via the application of an external magnet ${ }^{[9]}$.

Incorporation of positron emitters into liposomes has, simultaneously, attracted much attention. Many strategies have already been employed ${ }^{[10]}$. Many of them are based on the incorporation of a specific chelator inside, or on the surface of, the liposomes ${ }^{[11-13]}$. Some more exotic strategies involve the incorporation of radionuclides inside magnetic particles ${ }^{[14]}$. However, most of these systems suffer from demanding protocols, especially in terms of purification (use of column chromatography or centrifugation), hence they are not competitive with existing clinical protocols ${ }^{[15-17]}$.

The choice of the radionuclide is also crucial. There is a compromise between the radionuclide half-life $\left(\mathrm{t}_{1 / 2}\right)$ and the chemistry involved in the labeling process. For instance, ${ }^{18} \mathrm{~F}$ is used to label the glucose moiety to provide ${ }^{18} \mathrm{~F}-\mathrm{FDG}$, which is widely used in clinical protocols ${ }^{[18]}$. However, incorporation of radioactive fluorine into liposomes is often difficult to achieve as it requires several, often complex, synthetic steps ${ }^{[19,20]}$. Other radionuclides, for example, ${ }^{99 \mathrm{~m}} \mathrm{Tc}$ or ${ }^{64} \mathrm{Cu}$, are often used in liposome formulations.

However, the use of ${ }^{68} \mathrm{Ga}$ as positron emitter is appealing. Its physical half-life $\left(\mathrm{t}_{1 / 2}=68\right.$ $\min$ ) is compatible with clinical protocols and the chemistry involved in its chelation is well described. Furthermore, its on-site availability $\left({ }^{68} \mathrm{Ga}\right.$ generators are commercially available) make this radiotracer a suitable candidate for liposome-based PET tracers ${ }^{[21]}$.

Herein we report an original liposomal formulation involving coupling of a ${ }^{68} \mathrm{Ga}$-based 
radiotracer on the surface of UMLs $\left({ }^{68} \mathrm{Ga} @ \mathrm{UML}\right)$, allowing PET and MR imaging.

The magnetic properties of such a platform enable a rapid purification process $(\approx 10 \mathrm{~min})$, using a magnetic column, and can be used to target solid tumors in vivo via the effect of an external magnet on the tumor (magnetic accumulation) ${ }^{[8]}$. In addition to investigating the magnetic accumulation strategy, we also envisioned amplifying the vectorization potential of our platform by grafting glucose moieties onto the surface of the liposomes, thus taking advantage of the Warburg effect ${ }^{[22]}$. The combination of the two targeting strategies may actually increase the performance of the system, eventually offering an efficient theranostic probe.

\section{Materials and Methods}

Synthesis of magnetic nanoparticles. NPs of maghemite $\left(\gamma-\mathrm{Fe}_{2} \mathrm{O}_{3}\right)$ were synthesized by alkaline coprecipitation of $\mathrm{FeCl}_{2}$ and $\mathrm{FeCl}_{3}$ salts, according to the procedure described by Massart $^{[23]}$. After synthesis, the NPs were stabilized at $\mathrm{pH} 7$ with citrate molecules. The typical size of MNPs was $9 \mathrm{~nm}$ (polydispersity index $\sigma=0.35$ ). For the preparation of magnetic liposomes, MNPs were dispersed in a buffer $(0.108 \mathrm{M} \mathrm{NaCl}, 0.02 \mathrm{M}$ sodium citrate, $0.01 \mathrm{M}$ HEPES, $\mathrm{pH}=7.4$ ) to achieve a total concentration of $313 \mathrm{mg} \mathrm{mL}^{-1} \mathrm{MNPs}$.

Phospholipids. The following commercially available phospholipids were used for the preparation of liposomes: 1,2-dipalmitoyl-sn-glycero-3-phosphocholine (DPPC); 1,2distearoyl-sn-glycero-3-phosphocholine (DSPC); and 1,2-distearoyl-sn-glycero-3phosphoethanolamine-n-[(carboxy(polyethyleneglycol)2000](ammonium salt) (DSPEPEG2000). All were purchased from Avanti Polar Lipids, Inc (Birmingham, AL) and used in chloroform solutions.

Synthesis of DSPE-PEG2000-NODA and DSPE-PEG2000-Glu. Reactants were purchased from commercial sources and used without further purification. HRMS were recorded on a Bruker micrOTOF spectrometer, using Agilent ESI-L Low Concentration Tuning-Mix as reference.

Liposome preparation. The preparation of magnetic liposomes is described in the literature ${ }^{[8]}$. Briefly, a mixture of the different phospholipids in chloroform (total amount of phospholipids was typically $3.57 \mu \mathrm{mol}$ ) was diluted in $3 \mathrm{~mL}$ of diethyl ether and $1 \mathrm{~mL}$ of chloroform. Then 1 
$\mathrm{mL}$ of MNPs dispersed in water was introduced and sonication was carried out at room temperature for $30 \mathrm{~min}$ to yield a water-in-oil emulsion. This emulsion was immediately transferred to a $50 \mathrm{~mL}$ round bottom flask and the remaining organic solvent evaporated in a rotary evaporator (Rotavapor R-210, Buchi) at $25{ }^{\circ} \mathrm{C}$ until the gel phase disappeared. Liposomes were filtered through a $450 \mathrm{~nm}$ filter and subsequently purified by magnetic sorting. The solution containing UMLs was conditioned in syringes and placed on the edge of a strong magnet (Fe-Nd-B, 150 $100 \cdot 25 \mathrm{~mm}$; Supermagnete Inc.). Due to their high magnetic content the liposomes stuck to the magnet. The supernatant containing the free magnetic nanoparticles was then eliminated by removing the piston of the syringe. The operation was repeated three times to eliminate free MNPs.

The size of the liposomes was determined using a Zetasizer Nano ZS (Malvern, UK) at $90^{\circ}$ scattering angle. Samples of liposomes were diluted in an appropriate buffer. Diameters were deduced from the Stokes-Einstein law for spherical particles $\left(d=k_{B} T / 3 \pi \eta D\right.$, where $D$ is the translational diffusion coefficient, $\mathrm{k}_{\mathrm{B}}$ is the Boltzmann constant, and $\eta$ is the dispersant viscosity). Liposomes were also characterized by TEM (JEOL 100-CX transmission electron microscope) at $60 \mathrm{keV}$

In this study, three sets of liposomes were prepared: NODA@UML, Glu@UML and GluNODA@UML (see Table 1 in the Results part).

Radiolabeling. ${ }^{68} \mathrm{Ga}$ was eluted from a ${ }^{68} \mathrm{Ge} /{ }^{68} \mathrm{Ga}$ generator system (Eckert and Ziegler, Germany) with $\mathrm{HCl}(0.1 \mathrm{M})$. The $\mathrm{pH}$ of the peak fraction eluate $(1900 \mu \mathrm{L}, 0.1 \mathrm{M}, 343 \mathrm{MBq})$ was adjusted to $3 / 3.5$ with sodium acetate $(200 \mu \mathrm{L}, 1 \mathrm{M})$ and ultrapure water $(550 \mu \mathrm{L})$. A suspension of NODA@UML $(250 \mu \mathrm{L}$ in buffer solution $0.108 \mathrm{M} \mathrm{NaCl}, 0.02 \mathrm{M}$ sodium citrate, 0.01 M HEPES, $\mathrm{pH}=7.4$ ) was added and the resulting mixture was stirred at $80{ }^{\circ} \mathrm{C}$ for $15 \mathrm{~min}$ to obtain ${ }^{68} \mathrm{Ga} @ \mathrm{UML}$.

Purification. The resulting labeled liposomes ${ }^{68} \mathrm{Ga} @ \mathrm{UML}$ were separated from unchelated radioactive nuclei with a magnetic column $\left(\mathrm{MACS}^{\circledR}\right.$ columns, Miltenyi Biotec) (See Scheme 1 in the Results part). The column was wetted with $500 \mu \mathrm{L}$ of buffer prior to use. Then $500 \mu \mathrm{L}$ of the reaction medium (F1) was introduced in the magnetic column and eluted. After collection of the first fraction, the column was rinsed twice with buffer $(2 \times 500 \mu \mathrm{L}$ buffer solution 0.108 $\mathrm{M} \mathrm{NaCl}, 0.02 \mathrm{M}$ sodium citrate, 0.01 M HEPES, $\mathrm{pH}=7.4, \mathrm{~F} 2-\mathrm{F} 3$ ). The magnet was removed and the column was eluted with $500 \mu \mathrm{L}$ of buffer solution in order to collect the radiolabeled 
liposomes ${ }^{68} \mathrm{Ga} @ U$ UML (F4). To ensure their radiochemical purity (no free ${ }^{68} \mathrm{Ga}^{3+}$ ), the activities from the aliquots and the column after purification were measured.

Stability of ${ }^{68} \mathbf{G a} @$ UML in buffer. To determine stability, $3 \times 100 \mu \mathrm{L}$ of ${ }^{68} \mathrm{Ga} @$ UML from F4 were mixed with $3 \times 1 \mathrm{~mL}$ of buffer solution $(0.108 \mathrm{M} \mathrm{NaCl}, 0.02 \mathrm{M}$ sodium citrate, 0.01 $\mathrm{M}$ HEPES, $\mathrm{pH}=7.4$ ). After $30 \mathrm{~min}, 1 \mathrm{~h}$, and $2 \mathrm{~h}$ at room temperature, $500 \mu \mathrm{L}$ of each sample was introduced in the Miltenyi column previously wetted with $500 \mu \mathrm{L}$ of buffer. After collection of the first fraction (A1), the column was rinsed twice with buffer $(2 \times 500 \mu \mathrm{L}$ buffer solution $0.108 \mathrm{M} \mathrm{NaCl}, 0.02 \mathrm{M}$ sodium citrate, 0.01 M HEPES, $\mathrm{pH}=7.4$, A2-A3). The magnet was removed and the column was eluted with $500 \mu \mathrm{L}$ of buffer solution in order to collect the magnetic liposomes (A4). Activity of the fractions was measured in an activimeter and activity from the column was measured in a gamma counter (Wallac Wizard, Perkin Elmer).

Relaxation. Relaxation times were measured at 0.9 T using a Minispec MQ20 spectrometer (Bruker, France) at $25^{\circ} \mathrm{C}$. T1 and T2 were determined three times for each sample. Standard deviations were $2 \%$ and $5 \%$, respectively. Samples were diluted in buffer.

Transmission electron microscopy. After synthesis, liposomes were diluted 2000 times. A droplet was then deposited on a carbon-coated copper grid and dried. Liposomes were characterized with a JEOL 100-CX transmission electron microscope at $60 \mathrm{keV}$.

Cell culture and tumor-bearing mice. All animal experiments were carried out in compliance with current French legislation relating to the conduct of animal experimentation. Human glioblastoma U87MG cells (ATCC, Rockville, MD) were grown routinely in RPMI-1640 medium (Sigma-Aldrich), enriched with 10\% fetal bovine serum, 5\% L-glutamine, and 5\% penicillin-streptomycin. Female Swiss nude mice (6 weeks old; Charles River, France) were subcutaneously inoculated into the right and left posterior legs with U87MG cells $\left(1 \times 10^{6}\right)$ suspended in a 1:1 mixture of matrigel (BD Biosciences) and PBS, under the control of 1.5\% isoflurane in oxygen (Minerve). Four weeks after inoculation, the mice were enrolled in small animal PET and MRI imaging. The tumor volume $\left(\mathrm{V}_{\text {calliper }}\right)$ was estimated from the volume of an ellipsoid: $V_{\text {calliper }}=\pi / 6 \times D_{\text {long }} \times D_{\text {short }}^{2}$, where $D_{\text {long }}$ and $D_{\text {short }}$ were the longest and shortest diameters measured with a calliper. 
Magnetic resonance imaging. MRI imaging was performed with nonradioactive UML on U87MG tumor-bearing mice. Mice were divided into four groups. Groups 1 and $2(n=2)$ were injected with NODA@UML and groups 3 and $4(\mathrm{n}=2)$ were injected with GluNODA@UML. A Nd-Fe-B disc magnet (5 mm diameter, 3 mm height, Supermagnet Inc.) was strapped on the tumors of mice from groups 1 and 3 to test the magnetic accumulation strategy. In vivo MRI experiments were conducted on a preclinical 7T system (PharmaScan 70/16, Bruker), operating on the Paravision software platform (Brucker). Animals were installed in supine position in a mouse body volume coil (inner diameter $40 \mathrm{~mm}$ ) and maintained under general anesthesia with a $1.5 \%$ isoflurane/oxygen gas mixture inhalation $\left(100 \mathrm{~cm}^{3} \mathrm{~min}^{-1}\right.$ constant dose) delivered through a nose cone. Animals were scanned following standardized protocols, under respiratory-gated control. First a rapid sequence was performed for localizing the tumor site and after axial slices passing through the tumor site were acquired using highresolution T2-weighted sequences (repetition time/echo time TR/TE 3560/36 ms, flip angle $180^{\circ}, 1-\mathrm{mm}$ slice thickness; matrix $384 \times 384$, field of view $40 \mathrm{~mm}$ ). The animals were then removed from the machine, underwent retro-orbital injection of the venous sinus with $20 \mu \mathrm{M}$ of iron ( $17 \mu \mathrm{L}$ of $\mathrm{UML}$ in $100 \mu \mathrm{L}$ of buffer). The magnet was maintained $1 \mathrm{~h}$ after iv injection (Groups 1 and 3) and removed before MRI imaging. Finally, the animals were placed in the animal holder and underwent follow-up scanning using exactly the same acquisition parameters. All images on T2-weighted sequence were performed with a very long echo time, the aim of which was to be sensitive to iron oxide detection and not to optimize for assessing blood-to-tissue contrast.

Positron emission tomography imaging. PET imaging was performed with the Mosaic animal PET system (Philips Medical Systems, Cleveland, OH). Mice were anesthetized with a mixture of $1.5 \%$ isoflurane and oxygen, and maintained on a heating pad during biodistribution of the different tracers. First, U87MG tumor-bearing mice $(n=10)$ were injected with ${ }^{18}$ F-FDG (CisBio, France) to ensure the homogeneous metabolic activities of the tumors. After a fasting period of $5 \mathrm{~h}$, mice were injected in the retro-orbital sinus with $3 \pm 1.1 \mathrm{MBq}$ of ${ }^{18} \mathrm{~F}-\mathrm{FDG}$ and underwent imaging $1 \mathrm{~h}$ later. Static acquisitions were performed during an exposure time of 10 min. Three days after ${ }^{18}$ F-FDG injection, comparative PET imaging was performed with ${ }^{68} \mathrm{Ga} @$ UML and Glu- ${ }^{68} \mathrm{Ga} @$ UML. Mice were divided into two groups, the first group $(\mathrm{n}=5)$ was injected with ${ }^{68} \mathrm{Ga} @$ UML and the second $(n=5)$ was injected with Glu- ${ }^{68} \mathrm{Ga} @ \mathrm{UML}$. After a fasting period of $5 \mathrm{~h}$, animals were injected (150-200 $\mu \mathrm{L}, 3 \pm 1 \mathrm{MBq})$ and were imaged 
within an optimal time of $30 \mathrm{~min}$ after injection during static acquisition of $10 \mathrm{~min}$. A Nd-Fe-B disc magnet ( $5 \mathrm{~mm}$ diameter, $3 \mathrm{~mm}$ height, Supermagnet Inc.) was placed on the right tumors $\left(\mathrm{T}_{\text {right }}\right)$ just after injection and removed before PET imaging.

Images were reconstructed and data were analyzed using PETView and Syntegra software (Philips Medical Systems). Regions of interest (ROI) were drawn around tumors and whole mouse and tracer uptake was quantified using radioactivity concentration in ROI, reported to the whole mouse, and expressed as percentage of injected activity (\% IA).

Ex vivo tumor uptake. After imaging, 40 min after injection of ${ }^{68} \mathrm{Ga} @$ UMLs and Glu- ${ }^{68} \mathrm{Ga}-$ @UMLs, the U87MG tumor-bearing mice $(\mathrm{n}=10)$ were sacrificed and tumors were dissected, weighed, and counted in a gamma counter (Wallac Wizard, Perkin Elmer). Tumor uptake was expressed as percentage of injected dose/gram of tissue (\% ID/g), and corrected for decay.

Biodistribution. A microPET imaging study was performed in mice $(n=6)$ bearing only one U87MG tumor on one posterior leg. A first group of mice $(n=3)$ was injected with ${ }^{68} \mathrm{Ga} @$ UML and a second ( $\left.\mathrm{n}=3\right)$ was injected with ${ }^{68} \mathrm{Ga}-\mathrm{Glu} @ \mathrm{UML}$ and imaged 30 min post injection during $10 \mathrm{~min}$. A small Nd-Fe-B magnetic disc (5 mm diameter, height $3 \mathrm{~mm}$ ) was placed on the tumor of two mice / group just after injection. Ex vivo biodistribution was performed just after PET imaging.

\section{Statistical analysis}

Statistical analysis was performed using GraphPad 6 (GraphPad Software, CA). Results are presented as the mean \pm SD (standard deviation). Comparison between volumes was performed using Student's $t$ test. Analysis of data from PET imaging and ex vivo tumor uptake was performed using one-way ANOVA variance analysis with Holm-Sidak's test for multiple comparisons. A p-value $<0.05$ was considered statistically significant for all tests.

\section{Results and discussion}

Synthesis of DSPE-PEG2000-NODA. This new phospholipid consists of a classical DSPEPEG backbone terminated by a chelator NODAGA. Its synthesis can be achieved in one step, by coupling the commercially available DSPE-PEG2000 with NODAGA-NHS activated ester (CheMatech Inc.) (Scheme 1). Practically, both DSPE-PEG2000 (30 mg, $0.009 \mathrm{mmol}$ ) and 
NODAGA-NHS (7 mg, $0.009 \mathrm{mmol})$ were dissolved in $\mathrm{CHCl}_{3}(3 \mathrm{~mL})$, then triethylamine $(0.09 \mathrm{~mL})$ was added. The solution was stirred at room temperature. After, $12 \mathrm{~h}$ thin layer chromatography (TLC) using a mixture of $\mathrm{CHCl}_{3}$ and $\mathrm{MeOH}$ (4:1) as eluent and mass spectrometry both indicated consumption of starting material and formation of a new product. The reaction mixture was thus evaporated under vacuum and dialyzed ( 2500 cut-off) three times against water to afford the expected phospholipid DSPE-PEG2000-NODA (16 mg, 0.005 mmol) in 63\% yield as confirmed by mass spectrometry (see SI, figures 1-2) and by NMR (see SI, figures 3-5)

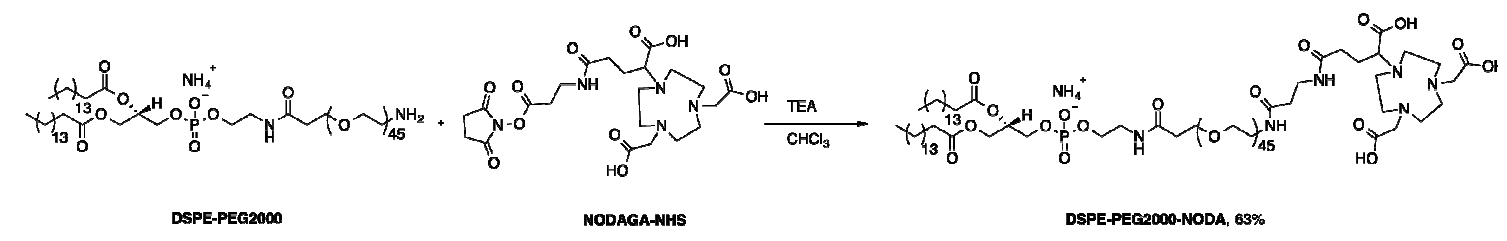

Scheme 1. Synthesis of DSPE-PEG2000-NODA

Synthesis of DSPE-PEG2000-Glu. This new phospholipid consists of a classical DSPE-PEG backbone functionalized with a glucose derivative via a peptide coupling. The synthesis of the carboxymethylglucoside is based on a four-step synthesis, starting from commercially available D-glucose adapted from the literature. ${ }^{1}$ DSPE-PEG2000-Glu was then synthesized via a peptidic coupling. Carboxymethylglucoside $(20 \mathrm{mg}, 0.09 \mathrm{mmol})$ was dissolved in DMSO $(1 \mathrm{~mL})$ together with DSPE-PEG2000- $\mathrm{NH}_{2}(2 \mathrm{~mL}, 50 \mathrm{mg}, 0.018 \mathrm{mmol})$ and pyridine $(0.2 \mathrm{~mL})$. N,N'-Dicyclohexylcarbodiimide (DCC) $(37 \mathrm{mg}, 0.18 \mathrm{mmol})$ was then added to the reaction mixture (Scheme 2). The reaction mixture was stirred at room temperature for $2 \mathrm{~h}$, and TLC using a mixture of $\mathrm{CHCl}_{3}$ and $\mathrm{MeOH}$ (4:1) indicated that the reaction was not complete, another portion of DCC (10 mg, $0.05 \mathrm{mmol})$ was added. After another $2 \mathrm{~h}$ of stirring, TLC indicated the completion of the reaction and disappearance of the starting material. The resulting mixture was centrifuged, the supernatant dialyzed (2500 cut-off) against water. The expected DSPE-PEG2000-Glu (23 mg, 7.7mmol) was obtained in $43 \%$ yield as confirmed by 
mass spectroscopy (see SI, figure 6) and NMR (see SI, figures 7-8).

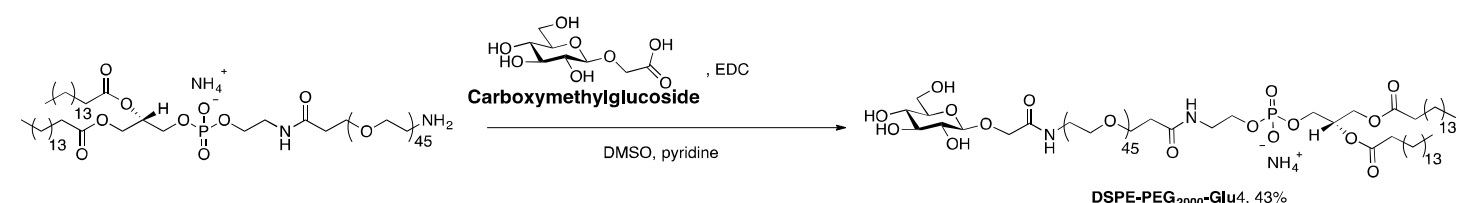

Scheme 2. Synthesis of DSPE-PEG2000-Glu

\section{Liposome formulation}

Maghemite $\gamma-\mathrm{Fe}_{2} \mathrm{O}_{3}$ nanoparticles $(9 \mathrm{~nm})$ coated with citrate ligands and dispersed in a buffer (0.01 M HEPES, $0.108 \mathrm{M} \mathrm{NaCl}, 0.02 \mathrm{M}$ sodium citrate, $\mathrm{pH}=7.4$ ) were used for the preparation of liposomes. The liposome formulation comprised NMPs, commercially available phospholipids (DSPE-PEG, DPPC, and DSPC) and the new chemically modified phospholipids, gathered into a single liposome. Two new phospholipids were synthesized from a DSPE-PEG2000 backbone to incorporate a glucose moiety DSPE-PEG2000-Glu and a NODAGA specific chelator into the lipid bilayer of the liposomes DSPE-PEG2000-NODA.

Liposomes were synthesized according to a reverse-phase evaporation method involving the evaporation of a water-in-oil emulsion. After collapse of the droplets during the evaporation step, bilayers formed, and liposomes were recovered using magnetic separation ${ }^{[8]}$. In this study, three sets of liposomes were prepared: NODA@UML, Glu@UML, GluNODA@UML (Table 1).

Table 1. Phospholipids composition (mol\%) for the three sets of UMLs.

\begin{tabular}{cccccc} 
mol \% & DPPC & DSPC & DSPE-PEG & $\begin{array}{c}\text { DSPE-PEG- } \\
\text { NODA }\end{array}$ & $\begin{array}{c}\text { DSPE-PEG- } \\
\text { Glu }\end{array}$ \\
\hline NODA@UML & 75 & 5 & 5 & 5 & 0 \\
\hline Glu@UML & 75 & 5 & 10 & 0 & 10 \\
\hline $\begin{array}{c}\text { Glu-NODA@ } \\
\text { UML }\end{array}$ & 75 & 5 & 5 & 5 & 10
\end{tabular}

As the ratio of PEG chains was kept constant (20\%) for all the formulations, no change in size was observed by TEM. Electron-dense spherical aggregates due to the presence of iron oxide nanoparticles were observed (Figure 1A). High magnification views confirmed the presence of 
nanoparticles trapped into these aggregates (Figure 1B and Figure 9 SI). The spherical shape corresponds to liposomes, the presence of the bilayer around was confirmed by cryo-TEM. ${ }^{[8]}$ The liposome diameters were measured by dynamic light scattering (DLS) and plotted with the intensity as a function of diameter (Figure 1C). Vesicles of $217 \mathrm{~nm}$ (polydispersity index $\sigma=$ 0.27 ) and $238 \mathrm{~nm}$ (polydispersity index $\sigma=0.18$ ) in diameter were recorded for NODA@UML (black) and Glu-NODA@UML (grey).

Typical size of liposomes may vary between 100 and $300 \mathrm{~nm}$ depending on the method of preparation. As expected, the hydrodynamic diameter measured by DLS increased after glucose grafting. For in vivo application this typical size is responsible of their short half-life that is why it is necessary to add PEG molecules in the bilayer formulation in order to avoid their rapid phagocytosis.

However for magnetic accumulation, it is the balance between the size and the magnetic force, which is the relevant parameter. The relative big size of the UML allows the encapsulation of a large amount of MNP yielding an efficient response to a magnetic field gradient.

The iron concentration on completion of the synthesis was measured by AAS and was almost constant $(\approx 1 \mathrm{~mol} / \mathrm{L})$. After synthesis, in order to avoid osmotic stress, the liposomes were dispersed in the same buffer as that used for the dispersion of the MNPs.
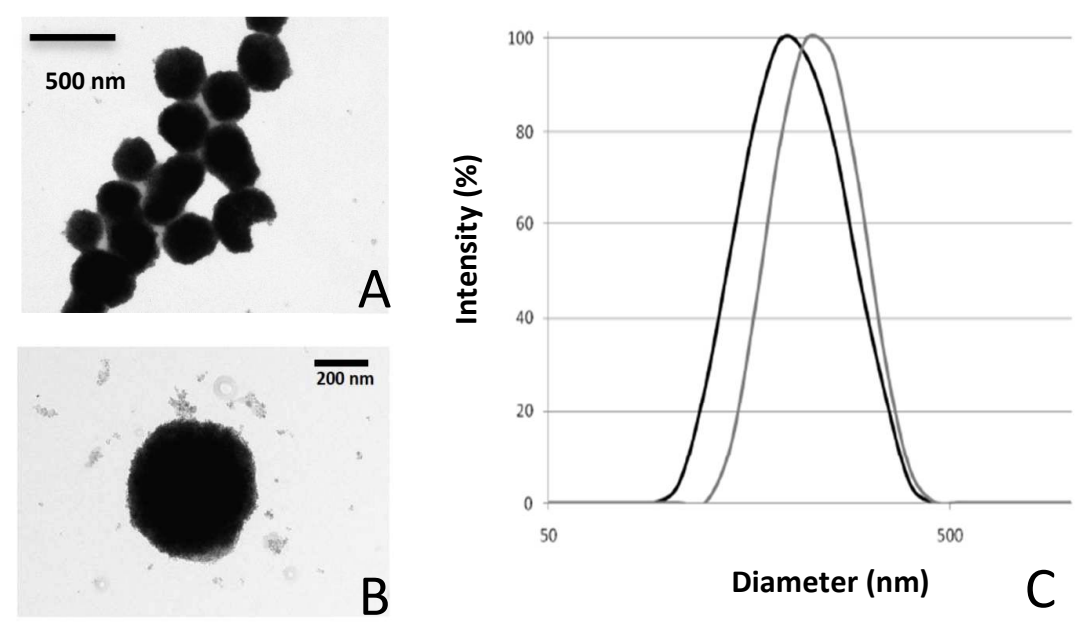

Figure 1. TEM images of NODA@UML: (A) overall view, (B) isolated liposome. The contrast is due to the presence of MNPs inside the core. (C) DLS data of NODA@UML (black) and Glu-NODA@UML (grey).

\section{Radiolabeling and purification}


Initial attempts to chelate ${ }^{68} \mathrm{Ga}^{3+}$ onto the liposomes at room temperature hardly reached $10 \%$ yield. The statistical distribution of the NODAGA inside and outside the liposomes, combined with the sterically demanding environment caused by the surrounding phospholipids, seemed to drastically restrict the labeling yield. However, after increasing the temperature, the liposomes became more permeable (no $\mathrm{Fe}_{2} \mathrm{O}_{3}$ NP leakage), allowing the chelation of the NODAGA located inside the liposomes. When the reaction was performed at $80^{\circ} \mathrm{C}$ for $15 \mathrm{~min}$, $80 \%$ yield of radiolabeling was achieved (see Table 2). The reaction conditions were compatible with clinical protocols. They are fully detailed in the supporting material.

Briefly, magnetic liposomes were added to a buffered mixture of water, sodium acetate, $\mathrm{HCl}$, and radioactive $\mathrm{Ga}^{3+}$, and reacted at $80^{\circ} \mathrm{C}$ for $15 \mathrm{~min}$. To purify the material from free $\mathrm{Ga}^{3+}$, the crude reaction mixture was injected into a magnetized column (MACS ${ }^{\circledR}$ column, Miltenyi Biotec), which allowed the retention of the magnetic liposomes while free radioactive species were eluted (Figure 2). Once all the free $\mathrm{Ga}^{3+}$ was removed (control of the activity of the eluted solutions F1, F2, F3), the column was removed from the magnet, and the pure radioactive liposomes, ${ }^{68} \mathrm{Ga} @ \mathrm{UML}(\mathrm{F} 4)$, were released. To ensure the purity of the liposomes (no free $\mathrm{Ga}^{3+}$ ), the activity from the aliquots and the column after purification was measured (Table 2). The same protocol was used for the radiolabeling of Glu-NODA@UML (Table 2).

Table 2. Activity of the aliquots during the purification process. The percentage of total activity is calculated as the ratio of the activity of the purified fractions of liposomes over the total activity of the crude reaction medium

NODA@UML

Glu-NODA@UML

\begin{tabular}{ccc|cc}
\hline Fractions & $\begin{array}{c}\text { Activity } \\
\text { (MBq) }\end{array}$ & $\begin{array}{c}\text { \% of total } \\
\text { activity }\end{array}$ & $\begin{array}{c}\text { Activity } \\
\text { MBq }\end{array}$ & $\begin{array}{c}\text { \% of total } \\
\text { activity }\end{array}$ \\
\hline F1 & 23.5 & 17.4 & 3.33 & 16.25 \\
F2+F3 & 3.1 & 2.3 & 0.98 & 4.78 \\
F4 ( ${ }^{\mathbf{8}} \mathbf{G a @ U M L s ) ~}$ & $\mathbf{1 0 7 . 1}$ & $\mathbf{7 9 . 3}$ & $\mathbf{1 4 . 3}$ & $\mathbf{6 9 . 8}$ \\
Column (after elution) & 1.4 & 1 & 1.88 & 9.18 \\
\hline Total & 135.1 & 100 & 20.49 & 100
\end{tabular}




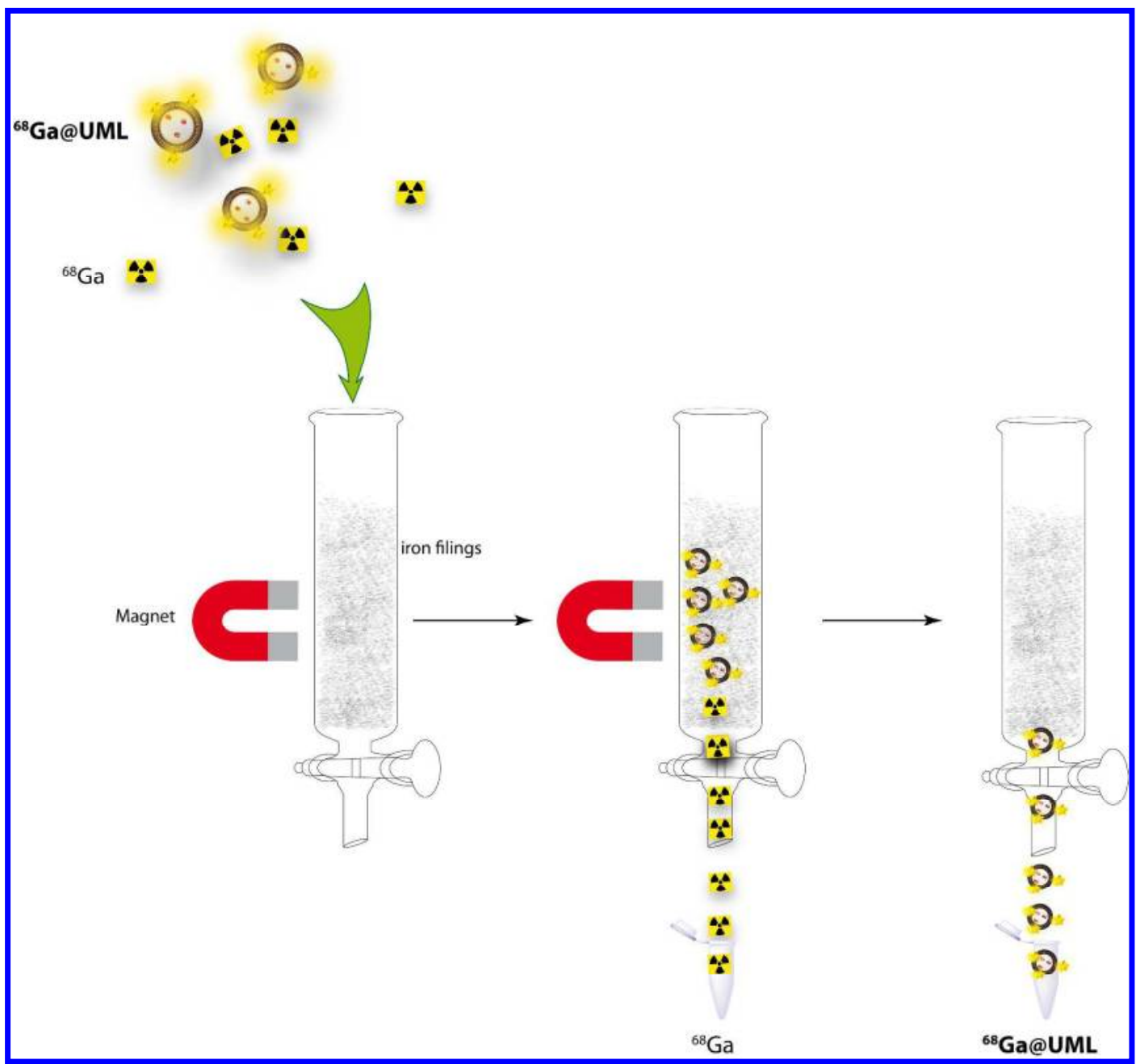

Figure 2. Purification step of ${ }^{68} \mathrm{Ga} @ U$ UML using a magnetized column (MACS® column, Miltenyi Biotec).

The stability over time of the ${ }^{68} \mathrm{Ga} @$ UML was evaluated in a buffer solution by measuring the corrected activity $30 \mathrm{~min}, 1 \mathrm{~h}$, and $2 \mathrm{~h}$ after labeling. Table 3 summarizes the activity measured in each aliquot after magnetic purification. We observed very good stability of the radiochemical purity after $2 \mathrm{~h}(85 \%)$, meaning that no release of gallium occurs during storage in buffer.

Table 3. Stability of the Ga@UMLs over time.

\begin{tabular}{cccc}
\hline Fractions & $\mathbf{3 0} \mathbf{~ m i n}$ & $\mathbf{1} \mathbf{h}$ & $\mathbf{2} \mathbf{h}$ \\
& $\mathbf{( \% )}$ & $\mathbf{( \% )}$ & $\mathbf{( \% )}$ \\
\hline $\mathrm{A} 1$ & 8.04 & 10.16 & 12.25 \\
$\mathrm{~A} 2+\mathrm{A} 3$ & 1.52 & 1.92 & 2.20 \\
$\mathrm{~A} 4\left({ }^{6 \mathbf{8}} \mathbf{G a} @ \mathbf{U M L}\right)$ & $\mathbf{9 0 . 4 4}$ & $\mathbf{8 7 . 9 2}$ & $\mathbf{8 5 . 5 6}$ \\
\hline
\end{tabular}


The integrity of the ${ }^{68} \mathrm{Ga} @$ UMLs after radiolabeling and purification was also checked. The liposome structure might be altered by the temperature $\left(80^{\circ} \mathrm{C}\right), \mathrm{pH}<4$, and the magnetic separation. Monitoring of the different stages involved in liposome preparation was carried out with TEM. Radiolabeling was performed with a stable isotope of Ga $\left({ }^{69} \mathrm{Ga}\right)$. TEM images before and after complexation with ${ }^{69} \mathrm{Ga}$ (Figures 3A and 3B) and after magnetic separation (Figure 2C) show a nonmodified structure of the UML. The white structure observed in the background of Figure $3 \mathrm{C}$ is due to the presence of salt.
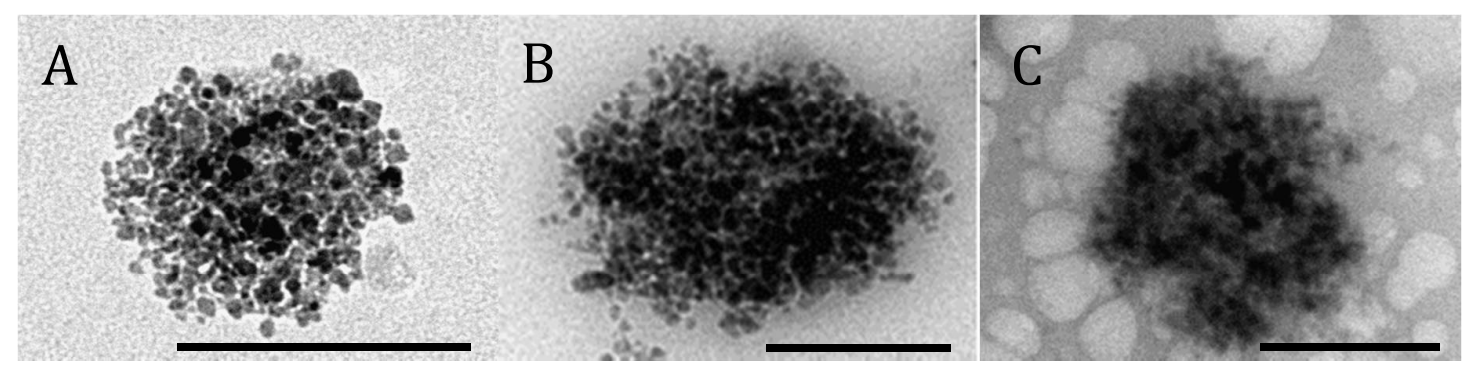

Figure 3. TEM images of magnetic liposomes: (A) before complexation, (B) after complexation with ${ }^{69} \mathrm{Ga}$, and (C) after magnetic separation. Bar scale: $200 \mu \mathrm{m}$.

Compared to other protocols described in the literature ${ }^{[14,17,25,26]}$, this process is rapid and simple to use in clinical and preclinical laboratories. It takes advantage of the magnetic properties of the liposomes, making purification simple (no chromatography or centrifugation required) and safe (no radiation outside the hood). From the radiolabeling reaction to the completion of the purification, this protocol can be carried out in $<30 \mathrm{~min}$ (15 $\mathrm{min}$ for labeling +10 min for purification). This is competitive with clinical protocols and compatible with the physical half-life of the radionucleide ${ }^{68} \mathrm{Ga}\left(\mathrm{T}_{1 / 2}=68 \mathrm{~min}\right)$. The different steps of the liposomes formulation are summarized on figure 4 . 


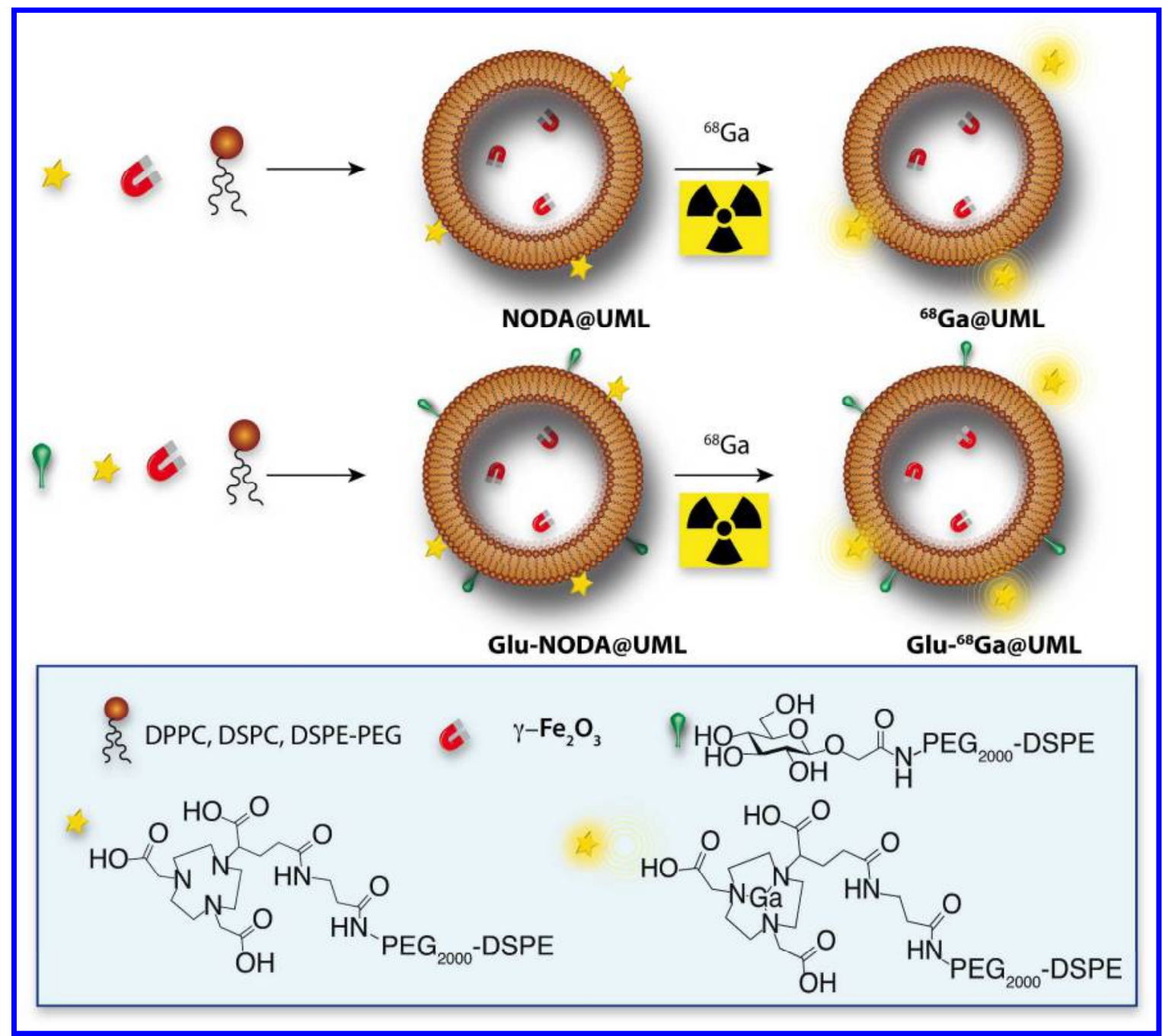

Figure 4. Ultra magnetic liposome (UML) formulations with the commercially available phospholipids (DPPC, DSPC, DSPE-PEG), the two phospholipids synthesized from DSPEPEG backbone DSPE-PEG-Glu and DSPE-PEG-NODA, and the magnetic nanoparticles $\left(\gamma \mathrm{Fe}_{2} \mathrm{O}_{3}\right)$. After synthesis NODA@UML and Glu-NODA@UML were radiolabeled with ${ }^{68} \mathrm{Ga}$.

\section{Relaxivity measurements}

Longitudinal $\left(\mathrm{r}_{1}\right)$ and transversal $\left(\mathrm{r}_{2}\right)$ relaxivities of magnetic liposomes as a function of lipid composition were measured and compared to values from free MNPs. Relaxivities were calculated from linear regression of the variation of the inverse of the relaxation time $T_{1}$ or $T_{2}$ versus $\mathrm{Fe}(\mathrm{III})$ concentration in the $0.01-0.1 \mathrm{mM}$ range (correlation coefficient $>0.99$ ). Results are tabulated in Table 4. 
Table 4. Relaxivities $r_{1}$ and $r_{2}$ of free MNP compared to the same particles encapsulated inside liposomes NODA@UML and Glu-NODA@UML

\begin{tabular}{|c|c|c|c|}
\hline & $\mathrm{r}_{1}\left(\mathrm{~s}^{-1} \mathrm{mM}^{-1}\right)$ & $\mathrm{r}_{2}\left(\mathrm{~s}^{-1} \mathrm{mM}^{-1}\right)$ & $\mathrm{r}_{2} / \mathrm{r}_{1}$ \\
\hline MNP & 31 & 127 & 4.1 \\
\hline NODA@UML & 41 & 297 & 7.2 \\
\hline Glu-NODA@UML & 45 & 216 & 4.8 \\
\hline
\end{tabular}

Experimentally, the transversal relaxivity $r_{2}$ (spin-spin relaxation process) was found to be enhanced after encapsulation into liposomes (Table 4), confirming the efficiency of these systems as $T_{2}$ contrast agents. Actually, the core of densely packed MNPs generates high $r_{2}$ values due to the resulting high magnetic moment of the UMLs. It is well known that the higher the local iron concentration, the higher the $r_{2}$ value is. The lipid bilayer is also likely to play a role as a barrier to the exchange of water molecules between the interior and the exterior of the liposomes. That is why we observed, experimentally, an increase of the $r_{1}$ after encapsulation.

Hence, NODA@UML demonstrated a better MRI efficiency than free NPs. The $\mathrm{r}_{2} / \mathrm{r}_{1}$ ratio increased from 4.1 to 7.2 for MNPs when they became trapped (Table 4). This increase was less pronounced in the case of Glu-NODA@UML, probably due to the lower efficiency in encapsulation of the NPs in the core of the liposomes, as illustrated by their lower $\mathrm{r}_{2}$ values.

This evolution of relaxivity profile favors the efficient detection of UMLs by T2-weighted spin echo sequences and, furthermore, by $\mathrm{T} 2 *$-weighted gradient echo sequences, which are sensitive to local changes in susceptibility, as used during in vivo imaging of $\mathrm{UML}$ accumulation in tumors.

\section{Magnetic resonance imaging}

A hyposignal corresponding to dark zones (highlighted with white arrows) appears in the case of magnetic vectorization (Figure 5B) as well as glucose targeting (Warburg effect) (Figure 5D). The combined targeting (magnet + glucose, Figure 5F) also induced a hyposignal in the tumor. Hence, each of the targeting strategies seems to function individually. Whether their effects are additional is difficult to quantify with MRI experiments. This MRI study could not provide quantitative information on tumor uptake.

To demonstrate the ability of ${ }^{68} \mathrm{Ga} @$ UMLs to act as a PET/MRI tracer in vivo and to quantify the amount of tracer in a tumor, a suspension of ${ }^{68} \mathrm{Ga} @$ UMLs was injected into female nude mice bearing two xenografted tumors of glioblastoma. 


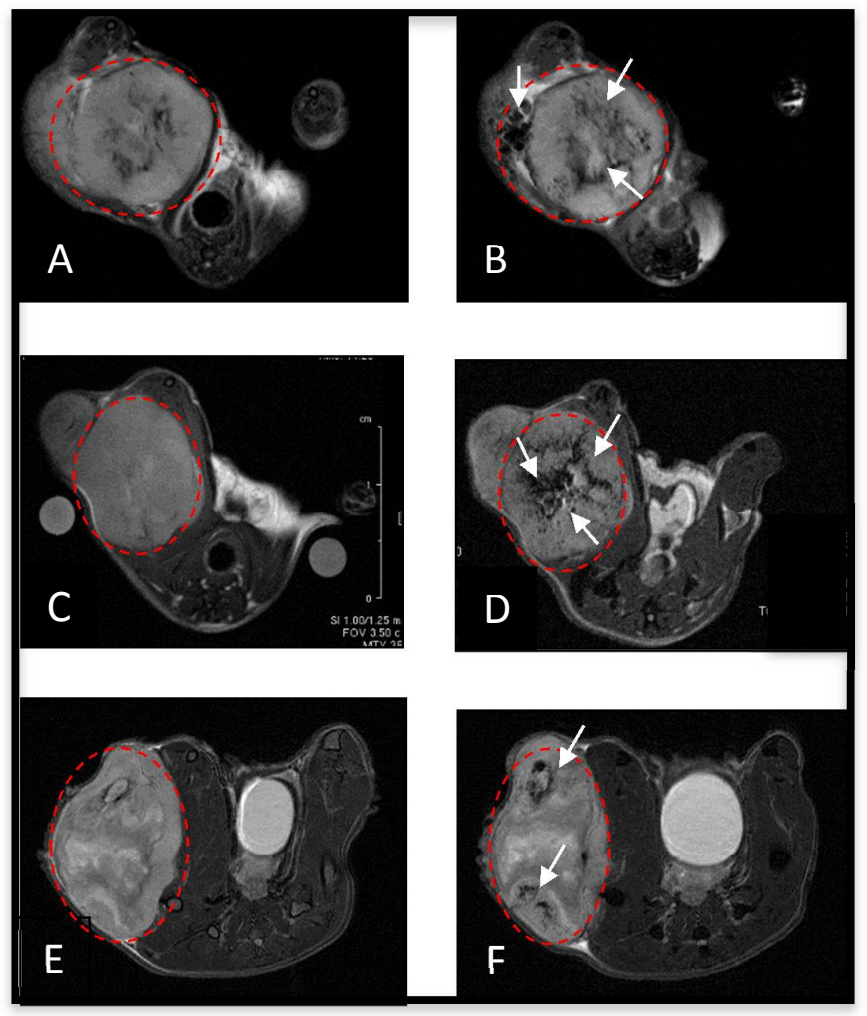

Figure 5. High-resolution T2-weighted sequence MRI images of solid tumors before injection (A), (C), and (E); and after injection of NODA@UML with magnet (B), Glu-NODA@UML without magnet (D), and Glu-NODA@UML with magnet (F). Tumors are highlighted by the red circles and white arrows show hyposignal pixels.

\section{In vivo PET imaging}

At the time of ${ }^{18}$ F-FDG PET imaging, 3 days before ${ }^{68} \mathrm{Ga} @$ UMLs injection, $\mathrm{V}_{\text {calliper }}$ of tumors were compared: the right tumor $\left(\mathrm{T}_{\text {right }}\right)$ volume was no different from the left tumor $\left(\mathrm{T}_{\text {left }}\right)$ volume $\left(418 \pm 139 \mathrm{~mm}^{3}\right.$ and $517 \pm 220 \mathrm{~mm}^{3}$, respectively, $\mathrm{p}=$ n.s. $)$.

${ }^{18}$ F-FDG PET imaging, as shown on representative coronal PET images, showed a physiological biodistribution of ${ }^{18} \mathrm{~F}-\mathrm{FDG}$ (Figures $6 \mathrm{~A}$ (a ; c). All tumors were clearly visualized with high contrast to background close to the tumor area, indicating high glucose metabolism. PET tumor volume was no different between $\mathrm{T}_{\text {right }}$ tumors $\left(335 \pm 95 \mathrm{~mm}^{3}\right)$ and $\mathrm{T}_{\text {left }}$ tumors $\left(334 \pm 108 \mathrm{~mm}^{3}\right)(\mathrm{p}=$ n.s. $)$. PET imaging analysis demonstrated a similar FDG uptake in right (Tr; $1.24 \pm 0.48 \%$ of IA) and left tumors (Tl; $1.28 \pm 0.52 \%$ of IA) $(\mathrm{n}=10, \mathrm{p}=$ n.s.) (Figure 6C). 
The magnetic targeting is able to accumulate ${ }^{68} \mathrm{Ga} @ \mathrm{UML}$ and Glu- ${ }^{68} \mathrm{Ga} @ \mathrm{UML}$ (Figures $6 \mathrm{~A}$ and $\mathrm{B})$ in the $\mathrm{T}_{\text {right }}$ tumor, compared to the non-vectorized contralateral tumor $\left(\mathrm{T}_{\text {left }}\right)$. $\mathrm{A}$ statistically significant difference was observed between tumors with magnetic targeting $(0.31$ $\pm 0.03 \%$ of IA $)$ and tumors without magnetic targeting $(0.13 \pm 0.08 \%$ of IA $)$ for ${ }^{68} \mathrm{Ga} @ \mathrm{UML}$ $\left({ }^{*} \mathrm{p}=0.001, \mathrm{n}=5\right)$ (Figure $\left.6 \mathrm{~B}\right)$. However, quantitative analysis shows a trend which was not statistically significant, between tumors with magnet $(0.19 \pm 0.13 \%$ of IA) and tumors without magnet $\left(0.10 \pm 0.03 \%\right.$ of IA) for the glycosylated Glu- ${ }^{68} \mathrm{Ga} @ \mathrm{UML},(\mathrm{p}=0.284, \mathrm{n}=5)$. (Figure 6B)

Ex vivo biodistribution performed on mice (see SI figure 10) injected with ${ }^{68} \mathrm{Ga}-\mathrm{UML}$ liposomes with (w/) or without (w/o) magnet showed high radioactivity accumulation in the liver (around 40 to $50 \%$ of ID/g $40 \mathrm{~min}$ pot injection) and spleen (10 to $20 \%$ of ID/g), which is one of the characteristics in liposome biodistribution. ${ }^{[26]}$

Ex vivo quantification (Figure 6C) confirmed the positive effect of the magnetic targeting. Without magnetic targeting, the amount of ${ }^{68} \mathrm{Ga} @ U M L$ accumulated in the tumor was $0.59 \pm$ $0.07 \% \mathrm{ID} / \mathrm{g}$, whereas in the presence of magnet the signal reached $1.38 \pm 0.16 \% \mathrm{ID} / \mathrm{g}$. Such an increase represents a gain of $134 \%$ on the targeting efficiency. In the case of Glu- ${ }^{68} \mathrm{Ga} @ \mathrm{UML}$, only a slight enhancement of $32 \%$ of the targeting efficiency was obtained by magnetic targeting $(0.78 \pm 0.19 \% \mathrm{ID} / \mathrm{g}$ and $0.54 \pm 0.08 \% \mathrm{ID} / \mathrm{g}$ with and without the magnet, respectively) (Figure 6C). This could be due to the formulation itself as we can see in figure 6A, after the injection of Glu- ${ }^{68} \mathrm{Ga} @ \mathrm{UML}(\mathrm{d})$, a high proportion of the dose remained at the injection point in contrary to what happened after ${ }^{68} \mathrm{Ga} @ \mathrm{UML}$ injection (b). In fact, the formulation of the liposomes with the glucose derivative probably induces an increase of the viscosity, leading to difficult injection and loss of a fair amount of the radiotracer. 


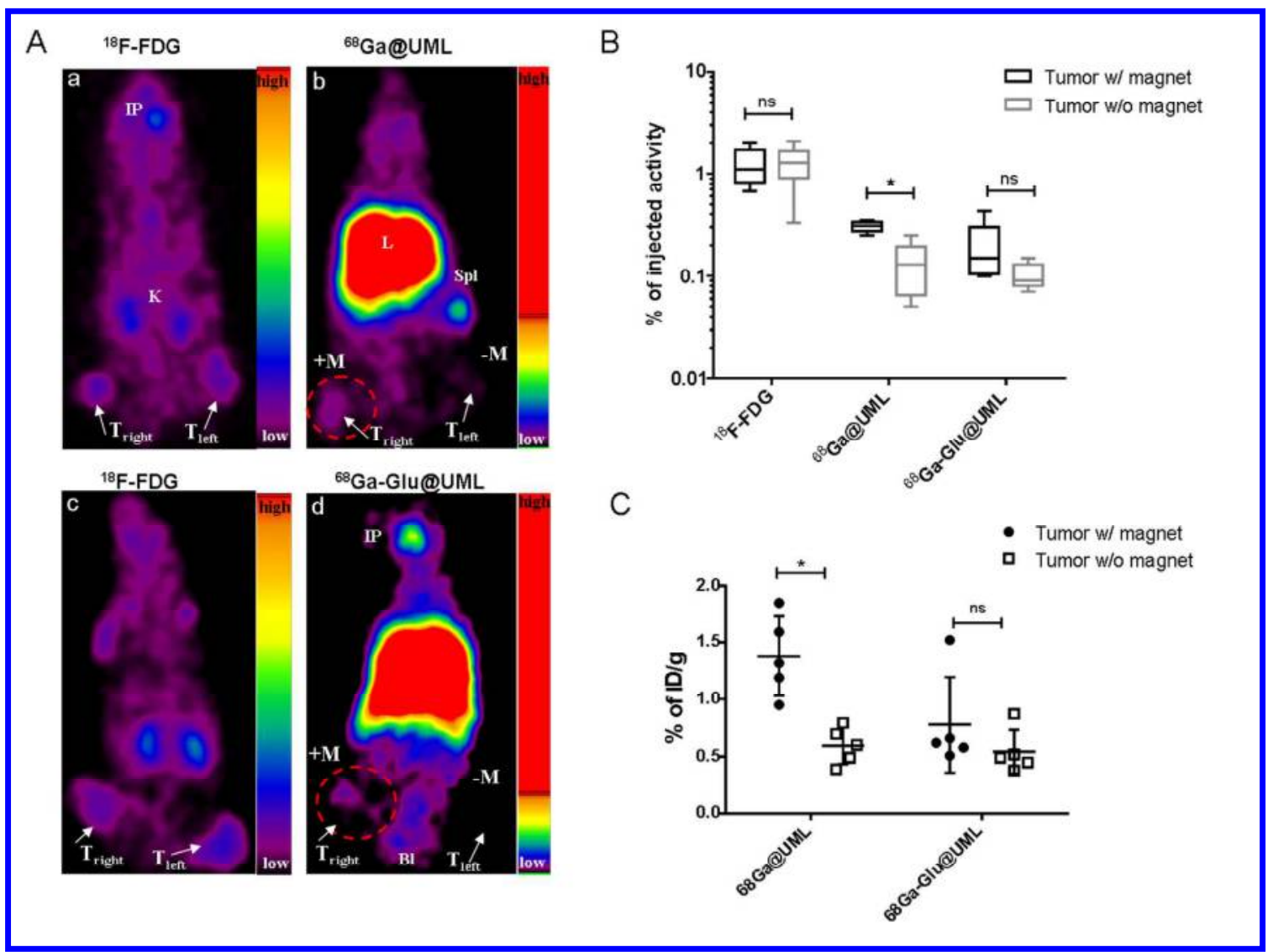

Figure 6. (A) Representative PET images (coronal slices) of mice bearing U87MG tumor on all posterior legs. Acquisitions (10 min static) started 60 min post injection for ${ }^{18} \mathrm{~F}-\mathrm{FDG}$ and 30 min for ${ }^{68} \mathrm{Ga} @$ UML or ${ }^{68} \mathrm{Ga}-\mathrm{Glu} @ U$ UML. Comparative images of two mice injected with ${ }^{18} \mathrm{~F}$ FDG (a;c) and, 3 days after, the same mice injected with ${ }^{68} \mathrm{Ga} @$ UML (b) or ${ }^{68} \mathrm{Ga}-\mathrm{Glu} @ \mathrm{UML}$ (d). The magnets were placed only on $\mathrm{T}_{\text {right }}$ tumors for UML tracers. The arrows show tumors, IP: injection point, K: kidneys, L: liver, Spl: spleen, Bl: bladder, $\mathrm{M}$ : magnet, $\mathrm{T}_{\text {right }}$ and $\mathrm{T}_{\text {left: }}$ : tumors.

(B) PET imaging analysis in tumors expressed as mean $\%$ of injected activity $(\% \mathrm{IA}) \pm \mathrm{SD}$. ( $\mathrm{n}=$ 10/group for ${ }^{18} \mathrm{~F}-\mathrm{FDG}$ and $\mathrm{n}=5$ for UML tracers.)

(C) Ex vivo quantification of UML tracers in tumors. Data are expressed as mean $\% \mathrm{ID} / \mathrm{g} \pm \mathrm{SD}$. $* \mathrm{p}<0.05$. 


\section{Conclusion}

In conclusion, we succeed in the synthesis of a new generation of liposomal formulations in which a ${ }^{68} \mathrm{Ga}$-based radiotracer is attached on the surface of ultra magnetic liposomes, allowing PET and MR imaging to localize and quantify the uptake of the liposomes in the target lesions. The technology developed for the purification of the radiolabeled liposomes is simple and easy to handle in the context of preclinical or clinical studies, with a very high labeling yield and a rapid magnetic purification. The ability of our platform to act as a PET tracer and a MRI contrast agent and to target solid tumors in mice (glioblastoma) was evaluated in vivo. Statistical image analysis shows preferential uptake of the liposome formulation in the tumor bearing the magnet. For the first time, we have been able to quantify the magnetic targeting efficiency ex vivo with a significant gain in tumor targeting. However, the effect of glucose targeting showed contradictory results: positive with MRI, but quantitatively inconclusive with PET. This may be due to the formulation itself that probably needs further optimization. Nonetheless, we have shown that it is possible to associate two targeting agents on this functional, and easy to handle platform. Moreover a drug could be added in the formulation leading to an interesting theranostic platform.

Acknowledgments. This work was supported by the LabEx MiChem part of French state funds managed by the ANR within Le Programme Investissements d'Avenir under reference ANR-11-IDEX-0004-02.

Supporting Information. Mass and NMR spectra of DSPE-PEG-NODA and DSPE-PEG-Glu molecules. High magnification TEM picture of UML. Biodistribution of UMLs.

\section{References}

[1] M. Ter-Pogossian, M. Phelps, E. Hoffman, N. Mullani, Radiology 1975, 114, 89-98. A positron-emission transaxial tomograph for nuclear imaging (PETT).

[2] C. Catana, D. Procissi, Y. Wu, M. S. Judenhofer, J. Qi, B. J. Pichler, R. E. Jacobs, S. R. Cherry, Proc. Natl.Acad.Sci. 2008, 105, 3705-3710. Simultaneous in vivo positron emission tomography and magnetic resonance imaging 
[3] M. S. Judenhofer, H. F. Wehrl, D. F. Newport, C. Catana, S. B. Siegel, M. Becker, A. Thielscher, M. Kneilling, M. P. Lichy, M. Eichner, et al., Nat. Med. 2008, 14, 459-465. Simultaneous PET-MRI: a new approach for functional and morphological imaging

[4] J. Choi, J. C. Park, H. Nah, S. Woo, J. Oh, K. M. Kim, G. J. Cheon, Y. Chang, J. Yoo, J. Cheon, Angew. Chem.Int.Ed. 2008, 47, 6259-6262. A Hybrid Nanoparticle Probe for DualModality Positron Emission Tomography and Magnetic Resonance Imaging

[5] R. Torres Martin de Rosales, R. Tavaré, R. L. Paul, M. Jauregui-Osoro, A. Protti, A. Glaria, G. Varma, I. Szanda, P. J. Blower, Aneew. Chem. Int. Ed. 2011, 50, 5509-5513. Synthesis of ${ }^{64} \mathrm{Cu}^{\mathrm{II}}$-Bis(dithiocarbamatebisphosphonate) and Its Conjugation with Superparamagnetic Iron Oxide Nanoparticles: In Vivo Evaluation as Dual-Modality PET-MRI Agent ${ }^{* *}$

[6] B. J. Pichler, A. Kolb, T. Nägele, H.-P. Schlemmer, J. Nucl. Med. 2010, 51, 333-336. Focus on molecular imaging pet/mri: Paving the Way for the Next Generation of Clinical Multimodality Imaging Applications

[7] G. Strijkers, W. M. Mulder, G. F. van Tilborg, K. Nicolay, Anticancer Agents Med. Chem. 2007, 7, 291-305. MRI contrast agents: current status and future perspectives.

[8] G. Béalle, R. Di Corato, J. Kolosnjaj-Tabi, V. Dupuis, O. Clément, F. Gazeau, C. Wilhelm, C. Ménager, Langmuir 2012, 28, 11834-11842. Ultra Magnetic Liposomes for MR Imaging, Targeting, and Hyperthermia

[9] M.-E Fernández Sánchez, S. Barbier, J. Whitehead, G. Béalle, A. Michel, H. LatorreOssa, C. Rey, L. Fouassier, A. Claperon, L. Brullé, et al., Nature, 2015, 523, 92-95.

Mechanical induction of the tumorigenic b-catenin pathway by tumour growth pressure

[10] B. S. Pattni, V. V. Chupin, V. P. Torchilin, Chem. Rev., 2015, 115 (19), 10938-10966. New Developments in Liposomal Drug Delivery

[11] J. W. Seo, H. Zhang, D. L. Kukis, C. F. Meares, K. W. Ferrara, Bioconjug. Chem. 2008, 19, 2577-2584. A Novel Method to Label Preformed Liposomes with ${ }^{64} \mathrm{Cu}$ for Positron Emission Tomography (PET) Imaging

[12] A. L. Petersen, T. Binderup, P. Rasmussen, J. R. Henriksen, D. R. Elema, A. Kjær, T. L. Andresen, Biomaterials 2011, 32, 2334-2341. 64Cu loaded liposomes as positron emission tomography imaging agents.

[13] W. T. Phillips, B. A. Goins, A. Bao, Wiley Interdiscip. Rev. Nanomedicine Nanobiotechnology 2009, 1, 69-83. Radioactive liposomes

[14] F. Chen, P. A. Ellison, C. M. Lewis, H. Hong, Y. Zhang, S. Shi, R. Hernandez, M. E. Meyerand, T. E. Barnhart, W. Cai, Angew. Chem. Int.Ed. 2013, 52, 13319-13323. ChelatorFree Synthesis of a Dual-Modality PET/MRI Agent ${ }^{\ddagger}$

[15] B. R. Jarrett, B. Gustafsson, D. L. Kukis, A. Y. Louie, Bioconjug. Chem. 2008, 19, 1496-1504. Synthesis of ${ }^{64} \mathrm{Cu}$-Labeled Magnetic Nanoparticles for Multimodal Imaging

[16] H.-Y. Lee, Z. Li, K. Chen, A. R. Hsu, C. Xu, J. Xie, S. Sun, X. Chen, J. Nucl. Med. 2008, 49, 1371-1379. PET/MRI dual-modality tumor imaging using arginine-glycine-aspartic (RGD)-conjugated radiolabeled iron oxide nanoparticles. 
[17] C. Glaus, R. Rossin, M. J. Welch, G. Bao, Bioconiug Chem. 2010, 21, 715-722. In Vivo Evaluation of 64Cu-Labeled Magnetic Nanoparticles as a Dual-Modality PET/MR Imaging Agent

[18] L. K. Shankar, J. M. Hoffman, S. Bacharach, M. M. Graham, J. Karp, A. A. Lammertsma, S. Larson, D. A. Mankoff, B. A. Siegel, A. V. den Abbeele, et al., J. Nucl. Med. 2006, 47, 1059-1066. Consensus Recommendations for the Use of ${ }^{18}$ F-FDG PET as an Indicator of Therapeutic Response in Patients in National Cancer Institute Trials

[19] A. Hoehne, D. Behera, W. H. Parsons, M. L. James, B. Shen, P. Borgohain, D. Bodapati, A. Prabhakar, S. S. Gambhir, D. C. Yeomans, et al., J. Am. Chem. Soc. 2013, 135 (48), pp 18012-18015 A ${ }^{18}$ F-Labeled Saxitoxin Derivative for in Vivo PET-MR Imaging of Voltage-Gated Sodium Channel Expression Following Nerve Injury

[20] F. Emmetiere, C. Irwin, N. T. Viola-Villegas, V. Longo, S. M. Cheal, P. Zanzonico, N. Pillarsetty, W. A. Weber, J. S. Lewis, T. Reiner, Bioconiug. Chem. 2013, 24, 1784-1789. ${ }^{18}$ FLabeled-Bioorthogonal Liposomes for In Vivo Targeting

[21] R. P. Baum, Theranostics 2012, 2, 437-447. Theranostics: From Molecular Imaging Using Ga-68 Labeled Tracers and PET/CT to Personalized Radionuclide Therapy - The Bad Berka Experience

[22] E. C. Calvaresi, P. J. Hergenrother, Chem.Sci. 2013, 4, 2319-2333. Glucose conjugation for the specific targeting and treatment of cancer.

[23] R. Massart, IEEE Trans.Magn. 1981, 17, 1247-1248. Preparation of aqueous magnetic liquids in alkaline and acidic media.

[24] A. Listkowski, P. Ing, R. Cheaib, S. Chambert, A. Doutheau, Y. Queneau, Tetrahedron: Asvmm. 2007, 18, 2201-2210, Carboxymethylglycoside lactones (CMGLs): structural variations on the carbohydrate moiety.

[25] J. Zhu, F. Yan, Z. Guo, R. E. Marchant, J. Colloid Interface Sci. 2005, 289, 542-550. Surface modification of liposomes by saccharides: Vesicle size and stability of lactosyl liposomes studied by photon correlation spectroscopy.

[26] Y.H. Bae, K. Park, J. Control Release, 2011, 153(3), 198-205. Targeted drug delivery to tumors: myths, reality and possibility. 
TOC

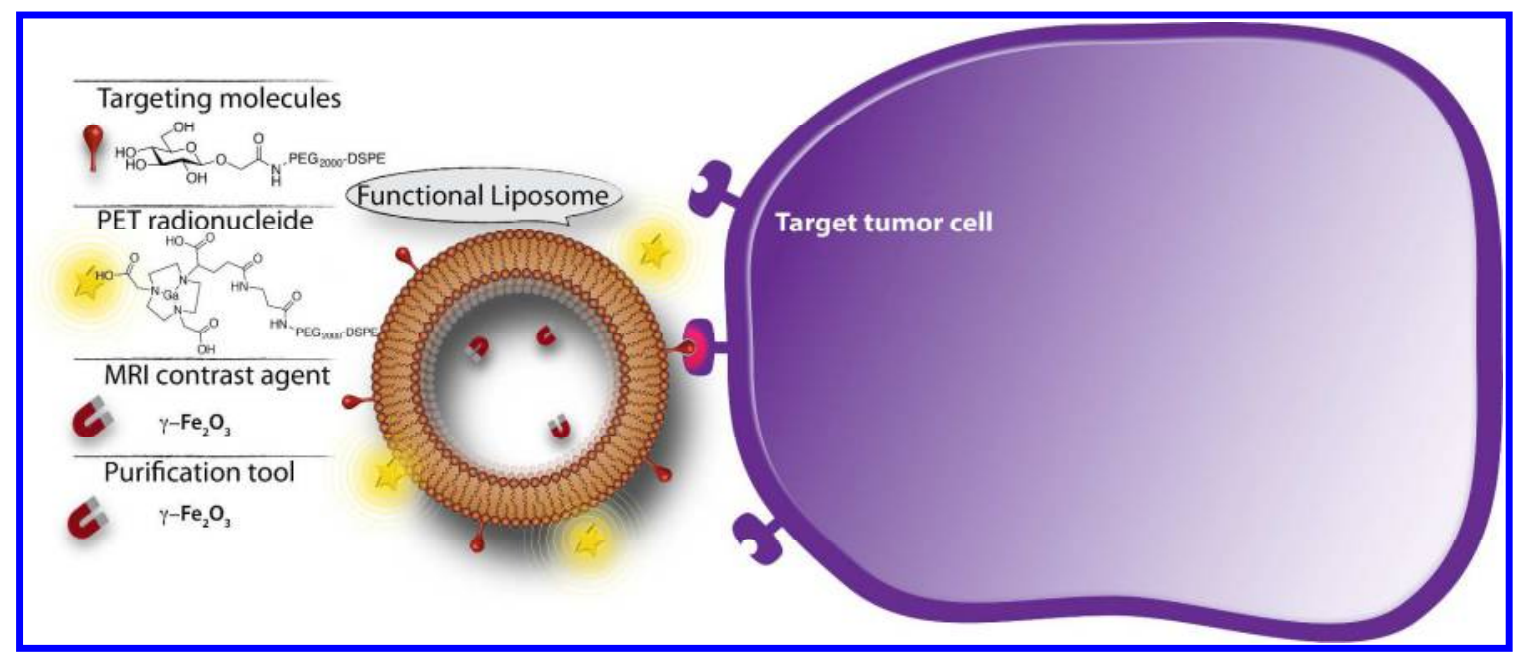

